\title{
Localization: A Modified DV-Hop Localization Algorithm in Wireless Sensor Network
}

\author{
Sakshi Aggarwal \\ Kurukshetra University \\ M.tech Scholar \\ JMIT, Radaur
}

\author{
Vikas Gupta \\ Kurukshetra University \\ Assistant Professor \\ JMIT, Radaur
}

\begin{abstract}
Today wireless sensor network has become a primal technology for different kinds of resourceful environment. Sensor node localization specifying where a given sensor node is physically or relatively located is extremely crucial for majority of the programmes in wireless sensor networks. Localization has been key out as one of the leading subject in Wireless Sensor Network (WSN). Many localization algorithms have been proposed for wireless sensor network. In the present work we first review and estimate the shortcomings of the self-positioning existing DV-HOP algorithm i.e. its localization error and accuracy. Finally, a more precise positioning modified DV-HOP algorithm has been presented. The work has been simulated in MATLAB.
\end{abstract}

\section{Keywords}

Wireless networks; localization; sensor network; DV-Hop; MATLAB; error estimation

\section{INTRODUCTION}

Among numerous applications of wireless sensor networks (WSN), precise location information of sensor nodes is critical to the success of the applications. Most data compiled from sensors are only meaningful when they are coupled with the location information of the corresponding sensors. To make every measurement useful to scientists, the location where measurements are taken has to be known. To measure the distance between neighbouring nodes, each sensor has to be armored with a ranging device. There are several ways to measure the distance between two sensors. Since each sensor is equipped with wireless communication capability in a wireless sensor network, the strength of received signals from neighbours can be used to estimate the corresponding distances. Localization is an important middle-ware service in wireless sensor networks. It renders location information to each individual node in the network over which services like event routing, reporting, data aggregation and many other superior level services can be built. This location cognizance allows each node to direct location stamped data back to a base station. Without the location information, the raw data would not be useful at the base station. Having location information also opens a wide range of interesting possibilities like geographic routing, target tracking etc.

\section{CLASSIFICATION OF LOCALIZATION}

There are various methods of localization of WSNs. These may be described as follows:

\subsection{Centralized vs. distributed computation}

There are two principal approaches to node localization in a WSN. The primary approach is centralized, where localization information of each node in the network is determined centrally through a computer typically at one edge of the network. The secondary approach applied in WSN localization is distributed in nature. The process is usually iterative, where sensor nodes undertake to localize themselves first and then assist the remaining nodes in the localization process.

\subsection{Range-Based vs. Range Free}

Some commonly used range based methods are Times of arrival (TOA), angle of arrival (AOA), Received signal strength measurement (RSSI) [16]. These provide higher accuracy in the localization of nodes. Range free methods works on connectivity of nodes in the network. As this method does not require costly hardware, it is most popular now days in researcher's community. Generally in the localization problem, the location of each sensor is predetermined before deployment. Sensors are installed to the assigned locations by human or by GPS (Global Positioning System). Obviously, this solution is inscalable as GPS is expensive as it cannot be used in indoor environments it is not possible to equip all nodes with such a device. Furthermore, it is sometimes infeasible to have manual configuration as the location information of sensors is unknown before actual deployment. Some localization algorithms provide localization information, which is relative to position of anchor nodes.

\section{RANGE FREE LOCALIZATION METHODS}

Because of the limitations of range-based schemes, many range-free solutions of the positioning system are presented. The DV-hop localization algorithm is intended by Niculescu and Nath [1,9] from American Rutgers University in which several perspectives have been examined with the optimal goal of location error reduction and also the various literature survey presented by different authors on DV-HOP algorithm $[2,3]$. S. Tian et. al. [4] proposed one of the enhancements over conventional DV Hop using RSSI to estimate the distance given reachable hops within radio range. In 2011, H. $\mathrm{Wu}$ and $\mathrm{R}$. Gao [5] introduced an improvement to adjust the hop size selection process where instead of using the least hop count as hop size, the averaging hop size was multiplied to the hop count resulting in low location error. In 2012, W. Yu and $\mathrm{H}$. Li [6] introduced a correction variable in order to adjust the distance using radio range information. Typical range-free localization algorithms includes APIT [7] Centroid [8], DVHop [9], MDS-MAP [10][11].

\section{DV-HOP ALGORITHM}

DV-hop is a standard simplex localization method for wireless sensor networks. It utilizes a modest amount of anchor nodes that cognize their location whereby other unknown nodes estimate their location from the information they incur. Using 
the principle of distance vector routing, the DV Based Positioning System has been implemented. The knownlocation nodes, called anchors, propagate their position packets across the network. Like DV routing, each other nodes after incurring the location packet will sustain a shortest hop count table. Based on this method, each anchor can commute the distance, in hops, to physical distance and propagate the calculating result to neighboring nodes. When an unknown node reckons its distance to three or more anchor nodes in the plane, execute maximum likelihood estimation to estimate the location of the unknown node. The algorithm execution is constitutes three steps [12][13]. In the first step, utilizing a standard distance vector protocol to exchange position and hop count information by broadcasting so that all nodes in the network incur the distances to reference nodes (known location nodes or anchor nodes) in order to reckon the minimum hop count to them.

In the second step, estimated an average size of one hop for the reference node which has the least measure of hops to others using hop count information (equation, here $h$ is number of hops between known nodes $i$ and $j$ ). The average hop-size is calculated by anchor using the following formula

$$
\text { HopSize }_{i}=\frac{\sum \sqrt{\left(x_{i}-x_{j}\right)^{2}+\left(y_{i}-y_{j}\right)^{2}}}{\sum h_{j}}
$$$$
\text { where } i \neq j
$$

$\operatorname{Here}\left(x_{i}, y_{i}\right),\left(x_{j}, y_{j}\right)$ are coordinates of anchor $\mathrm{i}$ and anchor $\mathrm{j}$, $h_{j}$ is the hops between beacon and beacon j. Once we have

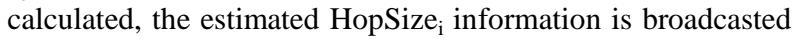
throughout all the network nodes.

Finally in the last step, unknown nodes compute the distance to the beacon nodes settled on hop-length and hops to the beacon nodes. Given a set of reference nodes where $n$ is the number of reckon nodes, let the hop value between the unknown node $X=(x, y)^{T}$ and the $\mathrm{i}^{\text {th }}$ reference node is $\mathrm{L}_{\mathrm{i}}$. Then the distance between the unknown node and $\mathrm{i}_{\text {th }}$ reference node is given by $d_{i}=L_{i} H_{o p}$. The unknown node location $\mathrm{X}$ can be obtained by formula given in equation (2)

$$
\begin{gathered}
\left(x-x_{1}\right)^{2}+\left(y-y_{1}\right)^{2}=d_{1}^{2} \\
\left(x-x_{2}\right)^{2}+\left(y-y_{2}\right)^{2}=d_{2}^{2} \\
\left(x-x_{n}\right)^{2}+\left(y-y_{n}\right)^{2}=d_{n}^{2}
\end{gathered}
$$

Equation (2) can be expanded as

$\left\{\begin{aligned} 2\left(x_{1}-x_{n}\right) x+2\left(y_{1}-y_{n}\right) y & =x_{1}^{2}-x_{n}^{2}+y_{1}^{2}-y_{n}^{2}-d_{1}^{2}+d_{n}^{2} \\ 2\left(x_{2}-x_{n}\right) x+2\left(y_{2}-y_{n}\right) y & =x_{2}^{2}-x_{n}^{2}+y_{2}^{2}-y_{n}^{2}-d_{2}^{2}+d_{n}^{2} \\ & \cdot \\ & \cdot \\ 2\left(x_{n-1}-x_{n}\right) x+2\left(y_{n-1}-y_{n}\right) y & =x_{n-1}^{2}-x_{n}^{2}+y_{n-2}^{2}-y_{n}^{2}-d_{2}^{2}+d_{n}^{2}\end{aligned}\right.$

In the form of linear equation $\mathrm{Ax}=\mathrm{b}$, the coordinates of $\mathrm{D}$ is computed by formula (4)

$$
\mathrm{A}=\left(\begin{array}{cl}
x_{1}-x_{n} & y_{1}-y_{n} \\
x_{2}-x_{n} & y_{1}-y_{n} \\
\cdot & \cdot \\
\cdot & \cdot \\
x_{n-1} & y_{n-1}
\end{array}\right) \quad \mathrm{B}=\left(\begin{array}{c}
d_{1}^{2}-d_{n}^{2}-x_{1}^{2}+x_{n}^{2}-y_{1}^{2}+y_{n}^{2} \\
d_{2}^{2}-d_{n}^{2}-x_{2}^{2}+x_{n}^{2}-y_{1}^{2}+y_{n}^{2} \\
\vdots \\
d_{1}^{2}-d_{n}^{2}-x_{1}^{2}+x_{n}^{2}-y_{1}^{2}+y_{n}^{2}
\end{array}\right)
$$

Coordinates of the unknown node (x,y) is computed as follows

$(x, y)=\left(A^{T} A\right)^{-1} A^{T} B$

\subsection{Problem analysis}

A Mobile Network consists of hundreds or thousands of nodes and a small number of data collection devices. Localization of these mobile nodes is an essential issue in mobile networks because many applications require the mobile to know their locations with a high degree of precision. Various localization methods based on mobile anchor nodes have been proposed for assisting the mobile nodes to determine their locations. However, none of these methods attempt to optimize the trajectory of the mobile anchor node. Most localization mechanisms use fixed anchors.

\subsection{Objectives}

4.1.1 To propose a path planning scheme which optimizes trajectory of the mobile anchor node to minimizes the localization error.

4.1.2 To compare the performance of proposed scheme based localization error to the DV-hop localization algorithm

\section{RESULTS AND DISCUSSION}

To minimize the localization error and improve the accuracy of DV-Hop algorithm following steps have been proposed:

Step1: Let us consider the position of few anchor nodes which are placed at random locations.

Step2: Now, let us vary the network size of these nodes placed in the surroundings.

Step3: The anchor nodes are fixed at four different points and hence different readings are taken by running the same program for different network sizes.

Step4: We calculate the different localization error by varying the network size as $100,200,300,400,500$.

Step4: For each network size, the number of unknown nodes is varied as 5,10 , and 15 .

Step5: For each varying network size, various simulations are observed, and correspondingly the localization errors for these simulations are observed.

Step6: The minimum localization errors of all the simulation run are noted.

Case1: when network size $=100$ sqm

Table 1

\begin{tabular}{|l|l|l|l|}
\hline s.no & $\begin{array}{l}\text { Network } \\
\text { size }\end{array}$ & $\begin{array}{l}\text { No. of } \\
\text { unknown } \\
\text { nodes }\end{array}$ & $\begin{array}{l}\text { Minimum error } \\
\text { reported(in } \\
\text { meters) }\end{array}$ \\
\hline 1. & 100 & 05 & 2.2669 \\
\cline { 3 - 4 } & & 10 & 1.0613 \\
\cline { 3 - 4 } & & 15 & 0.66084 \\
\hline
\end{tabular}

The table 1 shows the minimum localization error reported for network size of 100 sqm and different number of unknown nodes 
Case2: when network size $=200$ sqm

Table 2

\begin{tabular}{|l|l|l|l|}
\hline s.no & $\begin{array}{l}\text { Network } \\
\text { size }\end{array}$ & $\begin{array}{l}\text { No. of } \\
\text { unknown } \\
\text { nodes }\end{array}$ & $\begin{array}{l}\text { Minimum error } \\
\text { reported(in } \\
\text { meters) }\end{array}$ \\
\hline 1. & 200 & 05 & 2.502 \\
\hline & & 10 & 3.9928 \\
\hline & & 15 & 2.4262 \\
\hline
\end{tabular}

The table 2 shows the minimum localization error reported for network size of 200sqm and different number of unknown nodes.

Case3: when network size $=300$ sqm

\section{Table 3}

\begin{tabular}{|l|l|l|l|}
\hline s.no & $\begin{array}{l}\text { Network } \\
\text { size }\end{array}$ & $\begin{array}{l}\text { No. of } \\
\text { unknown } \\
\text { nodes }\end{array}$ & $\begin{array}{l}\text { Minimum error } \\
\text { reported(in } \\
\text { meters) }\end{array}$ \\
\hline 1. & 300 & 05 & 2.5594 \\
\hline & & 10 & 4.9708 \\
\hline & & 15 & 3.9496 \\
\hline
\end{tabular}

The table 3 shows the minimum localization error reported for network size of 300sqm and different number of unknown nodes.

Case4: when network size $=400$ sqm

Table 4

\begin{tabular}{|l|l|l|l|}
\hline s.no & $\begin{array}{l}\text { Network } \\
\text { size }\end{array}$ & $\begin{array}{l}\text { No. of } \\
\text { unknown } \\
\text { nodes }\end{array}$ & $\begin{array}{l}\text { Minimum error } \\
\text { reported(in } \\
\text { meters) }\end{array}$ \\
\hline 1. & 400 & 05 & 6.4228 \\
\hline & & 10 & 5.4697 \\
\hline & & 15 & 3.7135 \\
\hline
\end{tabular}

The table 4 shows the minimum localization error reported for network size of 400 sqm and different number of unknown nodes.

Case5: when network size $=500$ sqm

Table 5

\begin{tabular}{|l|l|l|l|}
\hline s.no & $\begin{array}{l}\text { Network } \\
\text { size }\end{array}$ & $\begin{array}{l}\text { No. of } \\
\text { unknown } \\
\text { nodes }\end{array}$ & $\begin{array}{l}\text { Minimum error } \\
\text { reported (in } \\
\text { meters) }\end{array}$ \\
\hline 1. & 500 & 05 & 1.4348 \\
\hline & & 10 & 8.1055 \\
\hline & & 15 & 4.1852 \\
\hline
\end{tabular}

The table 5 shows the minimum localization error reported for network size of 500sqm and different number of unknown nodes.

Case 6. Combined Scenario of all the five nework sizes
Table 6

\begin{tabular}{|l|l|l|l|}
\hline s.no & Network size & $\begin{array}{l}\text { No. of unknown } \\
\text { nodes }\end{array}$ & $\begin{array}{l}\text { Minimum } \\
\text { error } \\
\text { reported(in } \\
\text { meters) }\end{array}$ \\
\hline 1. & 100 & 05 & 2.2669 \\
\hline & & 10 & 1.0613 \\
\hline & & 15 & 0.66084 \\
\hline 2. & 200 & 05 & 2.502 \\
\hline & & 10 & 3.9928 \\
\hline & & 15 & 2.4262 \\
\hline 3. & 300 & 05 & 2.5594 \\
\hline & & 10 & 4.9708 \\
\hline & & 15 & 3.9496 \\
\hline 4. & 400 & 05 & 6.4228 \\
\hline & & 10 & 5.4697 \\
\hline & & 15 & 3.7135 \\
\hline 5. & 500 & 05 & 1.4348 \\
\hline & & 10 & 8.1055 \\
\hline & & 15 & 4.1852 \\
\hline
\end{tabular}

The table 6 shows the combined scenario of all the five nework sizes.

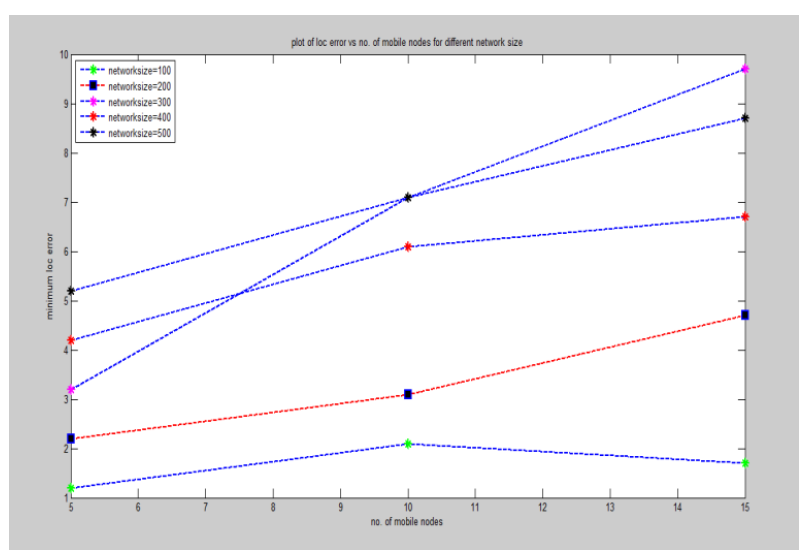

Figure: 1

This figure shows the MATLAB representation of all the combined scenario of all the five network sizes

The goal of our research work was to develop a scheme based on optimization of the trajectory of the mobile anchor node to improve the localization error. This goal is achieved by following a method which consists of following steps:

1. Wireless sensor network (WSN) is a set of sensor nodes connected to each other via wireless links, some node are anchor node and some are unknown which are simulated on the MATLAB.

2. DV-hop algorithm implementation in Matlab, and the simulation results are compared and analyzed.

3. In order to verify performance of our proposed algorithm against other algorithms viz. DV-Hop, simulations are conducted on MATLAB. The simulations of algorithms are randomly run many times for each result and the average values were used as final results. 


\section{TABLE FOR COMPARISON}

Table 7

\begin{tabular}{|c|l|c|c|}
\hline Year & Technique & $\begin{array}{l}\text { No. of } \\
\text { Unknown } \\
\text { Nodes }\end{array}$ & $\begin{array}{l}\text { Localization } \\
\text { Error }\end{array}$ \\
\hline 2014 & $\begin{array}{l}\text { A Selective 3- } \\
\text { Anchor DV- } \\
\text { Hop } \\
\text { Algorithm[15] }\end{array}$ & 20 & 40.66 \\
\hline 2017 & $\begin{array}{l}\text { Enhanced } \\
\text { DV-hop }\end{array}$ & 20 & 3.841587 \\
\hline
\end{tabular}

The table 7 shows the comparison of the localization erreor for two different authors when the no. of unknown nodes are same.

\section{COMPARISON BY GRAPH}

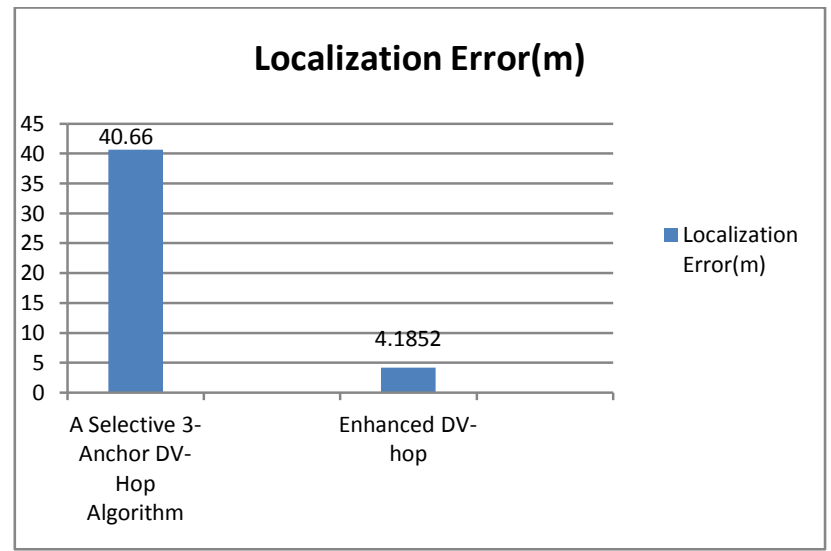

Figure: 2

This graph shows the comparison of localization error of two different authors when the no. of unknown nodes are similar.

\section{CONCLUSION}

This paper first encloses the original through the DV-Hop algorithm, pointing out its deficiencies, and analyzing the reasons for its deficiencies, as well as areas of enhancement. Based on this, a new algorithm for DV-Hop algorithm, known as the modified DV-HOP algorithm in wireless sensor network is introduced which optimizes the estimated error in the network and so the new calculation of the average hop distance calculation is more accurate, realistic position than the original algorithm, effectively reduces the error and the accuracy of the system is thus improved.

Finally, through MATLAB simulation experiments, analysis of the improved algorithm with the original algorithm positioning error and accuracy, confirming the improved algorithm greatly improved accuracy by reducing the error.

\section{ACKNOWLEDGMENTS}

The authors would like to sincerely thank the Management, Director, and the Head of the Department of Seth Jai Parkash
Mukand Lal Institute Of Engineering And Technology, JMIT, Radaur for their constant support and providing us with the required facility.

\section{REFERENCES}

[1] D. Niculescu and B. Nath, "Ad-hoc Positioning System", Global Tele communications Conference (GlobeCom), IEEE,Volume 5, Nov 25-29, 2001, pp. 2926-2931

[2] Chatterjee, A.: A Fletcher-reeves Conjugate Gradient Neural-Network-Based Localization Algorithm for Wireless Sensor Networks. IEEE Transactions on Vehicular Technology, Vol. 59, No.2, 823-830.(2010).

[3] Zou, Yi, and KrishnenduChakrabarty. "Sensor deployment and target localization based on virtual forces." INFOCOM 2003. Twenty-Second Annual Joint Conference of the IEEE Computer and Communications. IEEE Societies.Vol. 2.IEEE, 2003.

[4] S. Tian, X. Zhang, P. Liu, P. Sun, and X. Wang, "A RSSI-based DV-hop Algorithm for Wireless Sensor Networks," Proc. Int. Conf. Wireless Commun., Networking and Mobile Computing, pp. 2555-2558, 2007.

[5] H. Wu and R. Gao, "An Improved Method of DV-Hop Localization Algorithm," J. of Computational Information Systems, pp. 2293-2298, 2011.

[6] W. Yu and H. Li, "An Improved DV-Hop Localization Method in Wireless Sensor Networks," Computer Science and Automation Engineering, vol. 3, pp. 199202, 2012.

[7] He T, Huang C, Blum B M, et al. "Range-free localization schemes for large scale sensor networks", MobiCom2003, San Diego, 81-95, 2003

[8] N. Bulusu, J. Heidemann and D. Estrin, "GPS-less Low Cost Outdoor Localization for Very Small Devices", IEEE Personal Communications magazine, Volume 7, Issue 5, Oct. 2000, pp. $28-34$

[9] D. Niculescu and B. Nath, "DV based positioning in ad hoc networks," Telecommunications Systems, vol. 22, pp. 267-280, 2003.

[10] Y. Shang, W. Ruml, Y. Zhang, and M. Fromherz, "Localization from mere connectivity", Fourth ACM International Symposium on Mobile Ad Hoc Networking and Computing (MobiHoc), Annapolis, MD, Jan 2003.

[11] Y. Shang and W. Ruml, "Improved MDS-based Localization", IEEE InfoCom 2004, Hongkong, March 2004.

[12] Hichem Sassi, Tawfik Najeh, Noureddine Liouane,"A selective 3-Anchor DV-Hop Algorithm Based On the Nearest Anchor for Wireless Sensor Network";2014

[13] H. Liu, H. Darabi, P. Banerjee, and J. Liu, "Survey of Wireless Indoor Positioning Techniques and Systems," IEEE Trans. on Systems, Man, and Cybernetics, vol. 37, no. 6, pp. 1067-1077, 2007. 